\title{
Expression of epidermal growth factor receptor in breast carcinoma
}

\author{
S Lewis, A Locker, J H Todd, J A Bell, R Nicholson, C W Elston, R W Blamey, I O Ellis
}

\begin{abstract}
A series of 90 patients with primary operable breast cancer and with up to 36 months of follow up were investigated for expression of epidermal growth factor receptor (EGFR) in their tumours by immunocytochemical staining with the monoclonal antibody EGFR 1. Tumour samples were snap frozen in liquid nitrogen immediately after resection and subsequently stained using a standard indirect immunocytochemical method. Tumour staining was assessed by two observers and scored on a four point scale $(0-3)$. Thirteen (14\%) tumours showed positive immunoreactivity. A strong correlation between distinct EGFR expression and short disease free interval was observed. Significant correlations were also shown with oestrogen and progesterone receptor expression and tumour nuclear size. No significant association was found with tumour size, lymph node stage, and histological grade. The association with disease free interval remained significant in multivariate analysis.
\end{abstract}

Transforming growth factors are a subset of polypeptide growth factors which help to regulate normal cell growth and differentiation. Epidermal growth factor (EGF) is an essential factor in the development of mammary glands in mice. ${ }^{1}$ Animals susceptible to mammary tumours have a reduced tumour formation rate when the main body source of EGF, the submandibular gland, is removed. Mice in whom the salivary glands have been removed and injected with EGF have an increased incidence of tumour formation, ${ }^{2}$ and EGF has been shown to cause malignant transformation in fibroblast monolayers. ${ }^{3}$

In man, EGF has been shown to stimulate the growth of normal mammary epithelium ${ }^{4}$ and some cancer cell lines. ${ }^{56}$ Epidermal growth factor receptors (EGFR) have been found in normal human breast tissue and in human breast cancers. ${ }^{7}$ Recent work suggests that their presence in breast cancer is associated with a poor prognosis ${ }^{89}$ and has a negative relation with both oestrogen ${ }^{7-10}$ and progesterone receptor expression. ${ }^{7}$

Tumour size, lymph node stage, histological grade and tumour type are currently recognised as the most powerful predictors of prognosis in breast cancer, particularly when combined to form a prognostic index. ${ }^{11}$
Measurement of EGFR expression may offer an additional factor in assessing prognosis in patients with primary breast carcinoma. In this study we investigated the correlation between EGFR expression and oestrogen receptor, progesterone receptor content, histological grade, nodal stage and size of tumour and its relation to the disease free interval in a series of patients in the Nottingham/Tenovus Breast Cancer Study. ${ }^{11} 12$

\section{Methods}

The study comprised 90 consecutive patients presenting to the City Hospital between February 1984 and October 1986 with primary operable breast carcinoma. The criteria for operability were that the tumour should be $5 \mathrm{~cm}$ or less in maximum diameter as measured clinically and without spread to the skin or deep fixity. The diagnosis of carcinoma was generally made by Trucut needle biopsy specimen; a few patients required open biopsy with or without frozen section examination. Patients were counselled by an appropriately trained counselling sister and offered a choice between simple and subcutaneous mastectomy and tumour excision and subsequent whole breast irradiation.

Sixty patients underwent simple mastectomy, six received subcutaneous mastectomy, and 24 were treated by tumour excision and radiotherapy. Radiotherapy was given in the form of 45 Gray to the whole breast plus a 15 Gray boost to the tumour bed over six weeks using a 4 or $6 \mathrm{Mv}$ linear accelerator. Patients did not receive adjuvant hormone treatment or chemotherapy. Only those undergoing tumour excision received radiotherapy.

At the time of surgery nodes were sampled from the lower axilla, apex of the axilla, and the internal mammary chain via the second intercostal space in patients undergoing simple mastectomy. Patients undergoing subcutaneous mastectomy or tumour excision underwent biopsy of low axilla and internal mammary chain only. Lymph node staging was based on which of the sampled nodes were affected by metastatic tumour as follows: stage $A$, no nodal disease; stage $B$, low axillary node alone affected; stage $C$, apical or internal mammary node affected alone or in any other combination.

The excised tumours were measured fresh in the operating theatre laboratory. The tumours were bisected in two planes at right angles to one another and measurements made in three planes, again at right angles. Tumour size was taken as the largest of these three dimensions. 
Figure 1 Example of intense membrane immunoreactivity seen in a case of invasive breast carcinoma.

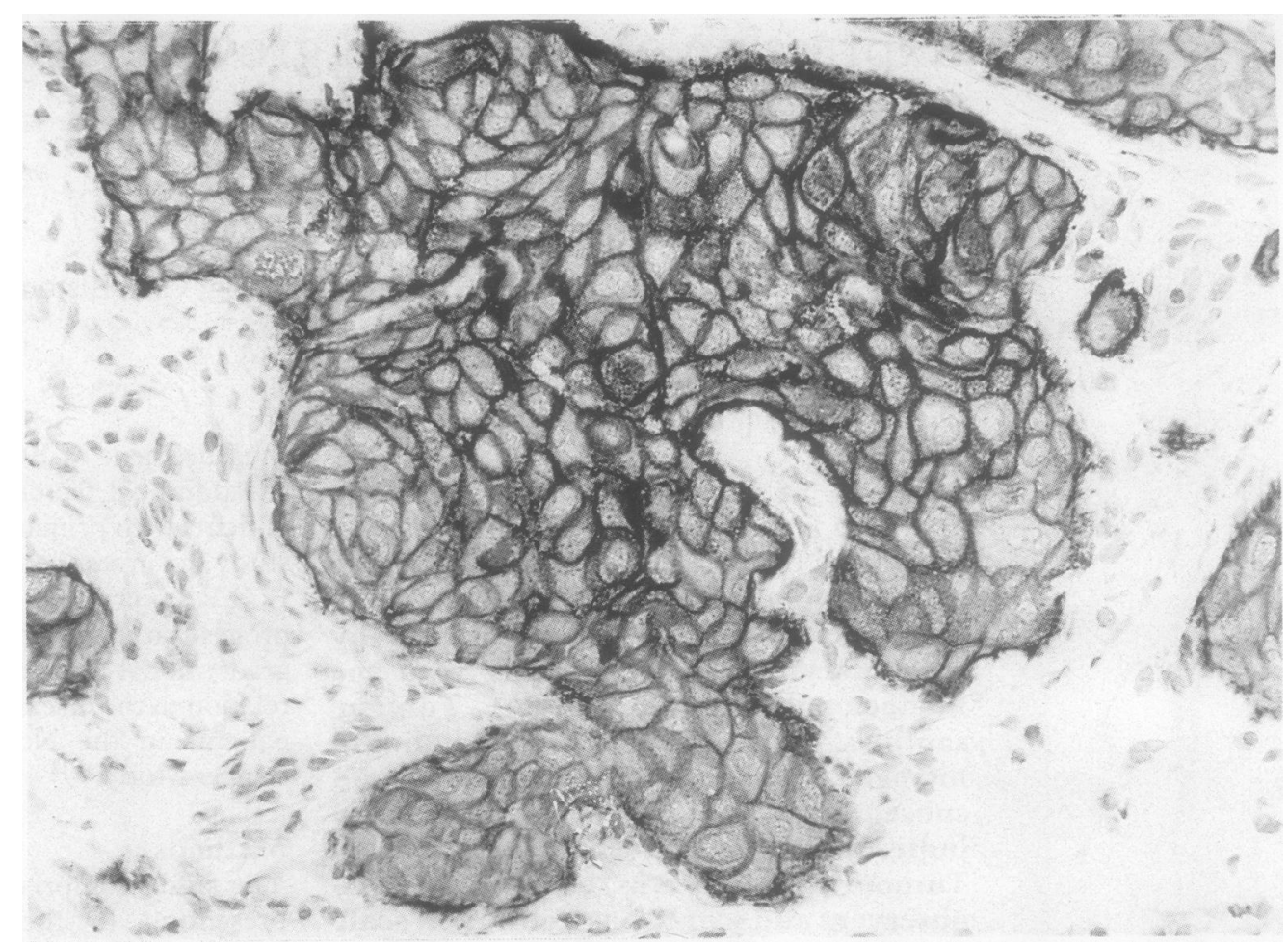

The tumour tissue was stained with a monoclonal antibody to EGFR using an indirect peroxidase method. Frozen sections $(4 \mu \mathrm{m})$ were cut at $4^{\circ} \mathrm{C}$, then dried at room temperature for two hours, before fixing in 50:50 acetone:chloroform at $4^{\circ} \mathrm{C}$ for 10 minutes. Sections were incubated with the monoclonal anti-EGFR antibody (EGFR1) at a 1/100 dilution in $1 / 5$ normal swine serum for 45 minutes. Rabbit anti-mouse peroxidase conjugate was then applied at a $1 / 50$ dilution in $1 / 5$ normal swine serum for 20 minutes. The sections were washed with TRIS-buffered saline between stages. Diaminobenzidine was used as the chromagen, with imidazole and copper sulphate enhancement. Haematoxylin was used as the counterstain. A section of normal skin was used as the positive control and omission of the primary antibody as the negative control.

Results were analysed by two observers independently according to the degree of tumour membrane staining and total amount of staining by allocating grades of $0,1,2$, and 3, 0 being no detectable staining; 1 very faint cytoplasmic reactivity; 2 distinct cytoplasmic reactivity; and 3 strong cytoplasmic reactivity or membrane reactivity (fig 1 ). For the purpose of this study 0 and 1 were regarded as negative and 2 and 3 as positive. It was felt this method was superior to radiological binding methods, because although subjective, it offered the

Table 1 Oestrogen receptor content and progesterone receptor content compared with EGFR expression

\begin{tabular}{|c|c|c|c|c|}
\hline & \multicolumn{2}{|c|}{ Progesterone receptor } & \multicolumn{2}{|c|}{ Oestrogen receptor } \\
\hline & Positive & Negative & Positive & Negative \\
\hline $\begin{array}{c}\text { EGFR Negative } \\
\text { Positive }\end{array}$ & $\begin{array}{r}44 \\
\chi^{2} \\
\text { (Yates }\end{array}$ & $\begin{array}{l}31 \\
9 \\
p=0.60 \\
\text { cction) }\end{array}$ & $\stackrel{54}{2} \chi^{2}=11$ & $\begin{array}{l}21 \\
10 \\
0.001 \\
\text { ection) }\end{array}$ \\
\hline
\end{tabular}

ability to observe the quality and quantity of staining actively associated with histologically malignant cells as opposed to total reactivity of tissue.

A sample of the fresh tumour was snap frozen in liquid nitrogen and sent for oestrogen receptor assay at the Tenovus Institute at Cardiff. Oestrogen receptor content was measured using the dextran coated charcoal method $^{13}$; a seven point assay was used and the results were computed by Scatchard analysis. Tumours with an oestrogen receptor content of greater than $10 \mathrm{fmol} / \mathrm{mg}$ cytosol protein were regarded as positive. Three tumours did not have oestrogen receptor and progesterone receptor content measured. Histological grade was assessed by Elston's modification of the Bloom and Richardson method ${ }^{14}$ by assessing nuclear pleomorphism, mitoses, and tubule formation. The Nottingham Prognostic Index Score ${ }^{11}$ is calculated by combining the results of lymph node stage, histological grade, and tumour size in the following manner:

Index $=$ stage $(1-3)+$ grade $(1-3)+($ size $\times 0 \cdot 2)$

After surgery all patients were followed up in a clinic and reviewed at three monthly intervals for 18 months in the case of mastectomy patients and for 24 months in those undergoing tumour excision and radiotherapy. Thereafter patients were reviewed six monthly for five years, then annually. No patients were discharged from follow up. Disease free interval was recorded as the time to first recurrence of local, regional, or metastatic disease. In this study two patients had distant metastatic disease at the time of surgery and were therefore excluded from analysis of disease free intervals.

\section{Results}

Positive immunoreactivity for EGFR was identified in $16(17.7 \%)$ patients and was 
Figure 2 Probability of disease free state against time of patients with EGFR positive and negative tumours.

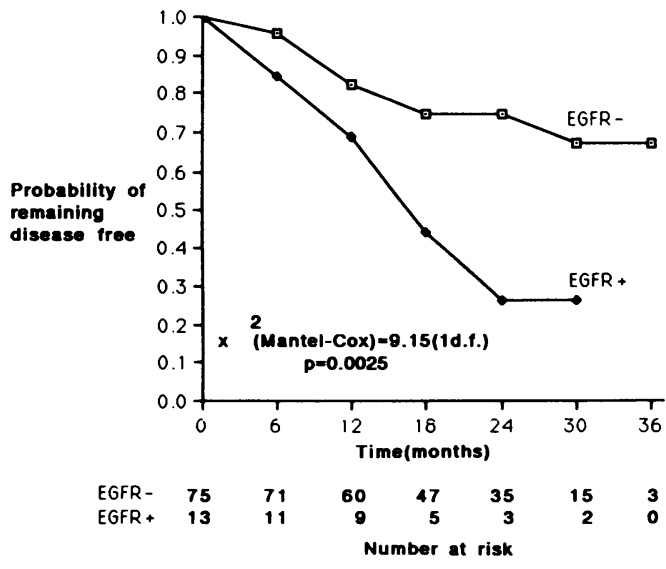

unequivocal (score 2 or 3 ) in $13(14 \%)$. An inverse relation was found between the presence of EGFR and expression of oestrogen receptor (table 1) and a similar trend for progesterone receptor expression (table 1), although this failed to reach significance. Overall, histological grade of the tumours was not related to EGFR expression (table 2), although one component, nuclear size, showed an association (table 3 ), indicating that tumours with large nuclei express EGFR more often. The other components of histological gradenamely, tubule formation and mitotic frequency-were not related to EGFR expression (tables 4 and 5). Lymph node spread and tumour size were not related to EGFR expression. There was no relation between the Nottingham Prognostic Index Score (calculated from the tumour size, lymph node stage, and histological grade) and EGFR state (table 6).

Life table analysis showed a strong correlation $(p<0.003)$ between the presence of EGFR and shorter disease free interval (fig 2). Lymph node stage and histological grade were also significantly associated with disease free interval. Tumour size, oestrogen and progesterone receptor content, however, showed no significant relation to disease free interval.

Combining oestrogen receptor and EGFR content has been advocated by some as a potentially useful method of stratifying patients into treatment groups. ${ }^{10}$ In our series we only had two patients who were oestrogen receptor positive and EGFR negative, precluding comprehensive analysis, but knowledge of EGFR expression can be used to identify a poor prognostic subgroup of patients with oestrogen receptor negative tumours (fig 3 ).

A Cox multivariate analysis was used to determine which of the variables studied had independent prognostic significance. ${ }^{15}$ Lymph node stage, histological grade, tumour size, oestrogen receptor and progesterone receptor

Table 2 Histological grade compared with EGFR expression

\begin{tabular}{clcc}
\hline & \multicolumn{3}{l}{ Histological grade } \\
\cline { 2 - 4 } & 1 & 2 & 3 \\
\hline EGFR Negative & 24 & 22 & 31 \\
Positive & $\stackrel{1}{8}$ & $8 \cdot 38(2 \mathrm{df}) \mathrm{p}=0 \cdot 18$ (Yates' correction) \\
& $\chi^{2}=3 \cdot 38$.
\end{tabular}

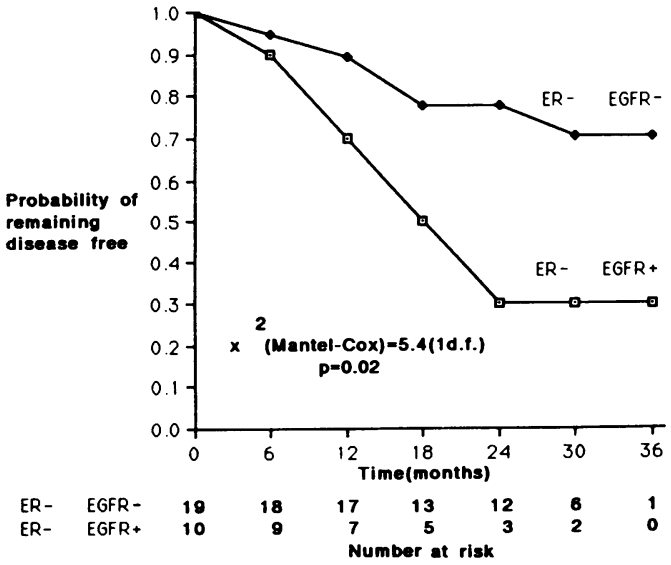

Figure 3 Probability of disease free state against time of patients with oestrogen receptor negative tumours which were epidermal growth factor receptor positive or negative.

content and EGFR expression were entered into the analysis. In the Cox analysis a $Z$ value of 1.96 or greater indicates that the variable is independently significant, while the $\beta$ coefficient is indicative of the relative power of that variable. Table 7 summarises the results of this analysis, showing that stage, grade, and EGFR were of independent significance. Oestrogen receptor and progesterone receptor content did not achieve significance. Omitting grade from the analysis improved the $\beta$ coefficient for EGFR (from 0.326 to 0.41). Using the $\beta$ coefficient for stage, grade, and EGFR studies, a prognostic index was calculated for each patient in a manner similar to that previously described from this unit and applied to patients with primary breast cancer. This new index was derived thus:

$$
\begin{gathered}
\text { Index }= \\
\quad(\text { stage } \times 0.64)+(\text { grade } \times 0.53) \\
\times \text { EGFR } \times 0.33)
\end{gathered}
$$

Index values were calculated for the 90 patients in this study. Using cut off values at intervals of 0.5 from a lowest value of 1.5 , curves were constructed for disease free interval in five subgroups. The results are shown in fig 4 . At one extreme a group of patients (1) was identified with an $80 \%$ chance of remaining disease free over 30 months of follow up. This contrasts with prognostic group 5, who had only a $20^{\circ}$ o probability of being disease free over the same period of follow up.

\section{Discussion}

EGF is a single chain polypeptide ${ }^{1617}$ found in almost all body fluids. ${ }^{18} \mathrm{EGF}$ binding to EGFR results in increased DNA synthesis and cell proliferation. There is increasing awareness that polypeptide growth factors, such as EGFR, are involved not only in the control of

Table 3 Nuclear size compared with expression

\begin{tabular}{clcc}
\hline \multicolumn{4}{c}{ Nuclear size } \\
\cline { 2 - 4 } & 1 & 2 & 3 \\
\hline EGFR Negative & 8 & 41 & 28 \\
Positive & 0 & 3 & 10 \\
& $\chi^{2}=7.75(2 \mathrm{df})$ & $\mathrm{p}=0.02$ & (Yates' correction) \\
\hline
\end{tabular}


Table 4 Lymph nodal stage (Nottingham) compared with EGFR expression

\begin{tabular}{llcc}
\hline & \multicolumn{3}{l}{ Lymph nodal stage } \\
\cline { 2 - 4 } & 1 & 2 & 3 \\
\hline $\begin{array}{lll}\text { EGFR Negative } \\
\text { Positive }\end{array}$ & $\begin{array}{l}49 \\
10\end{array}$ & 17 & 11 \\
& $\chi^{2} \stackrel{2}{=} 2.16(2 \mathrm{df}) \mathrm{p}=0.34$ (Yates' correction) \\
\hline
\end{tabular}

Table 5 Tumour size compared with EGFR expression

\begin{tabular}{cccc}
\hline & \multicolumn{3}{l}{ Size } \\
\cline { 2 - 4 } & 1 & 2 & 3 \\
\hline EGFR Negative & 43 & 33 & 1 \\
Positive & 4 & 8 & 1 \\
& $\chi^{2}=4 \cdot 24(2 \mathrm{df}) \mathrm{p}=0.12$ (Yates' correction) \\
\hline
\end{tabular}

Size definitions: $(1)=0-2 \mathrm{~cm} ;(2)=2-5 \mathrm{~cm} ;(3)=>5 \mathrm{~cm}$.

normal cellular growth and proliferation but also in as yet poorly understood ways in disease states, including cancer.

The study was undertaken to evaluate the prognostic potential of measurement of EGFR in primary breast cancer. An immunocytochemical method was chosen instead of a biochemical method, because of its ability to identify tumour positivity at a cellular level, excluding the influence of variance of tumour tissue cellularity. The prevalence of EGFR positivity of $14 \%$ is lower than that in other studies $-29 \%{ }^{2}$ and $26 \%{ }^{6}$ In our series only patients with primary operable breast cancer and not those with advanced disease were studied. This selection process may have had an influence on the number of positive cases. Only tumours with unequivocal distinct cytoplasmic or membrane reactivity were regarded as positive.

We have shown that there is a strong relation between EGFR expression and subsequent disease free interval. This concurs with the finding of Sainsbury et al in a study of 135 breast cancers. ${ }^{10}$ They also found a highly significant correlation between EGFR positivity and both early relapse and overall patient survival. We have not yet analysed survival data as the follow up of these patients is still limited.

EGFR positivity did not correlate in this

Table 6 Nottingham Prognostic Index compared with EGFR expression

\begin{tabular}{cccc}
\hline & $<3.4$ & $>3.4<5.4$ & $>5.4$ \\
\hline EGFR Negative & 31 & 33 & 13 \\
Positive & 2 & 9 & 2 \\
& $\chi^{2}=3.72$ & $(2 \mathrm{df}) \mathrm{p}=$ & 0.16 \\
\hline
\end{tabular}

Table 7 Cox analysis for disease free interval

\begin{tabular}{|c|c|c|c|}
\hline & $\beta$ coefficient $\dagger$ & $Z$ value & p value \\
\hline $\begin{array}{l}\text { Lymph node stage } \\
\text { Histological grade } \\
\text { EGFR } \\
\text { Oestrogen receptor } \\
\text { Progesterone receptor }\end{array}$ & $\begin{array}{l}0.6443 \\
0.5292 \\
0.3263 \\
\text { NS } \\
\text { NS }\end{array}$ & $\begin{array}{l}2 \cdot 59 \\
2 \cdot 08 \\
2 \cdot 17 \\
\text { NS } \\
\text { NS }\end{array}$ & $\begin{array}{l}0.01 \\
0.03 \\
0.04 \\
0.35 \\
0.18\end{array}$ \\
\hline
\end{tabular}

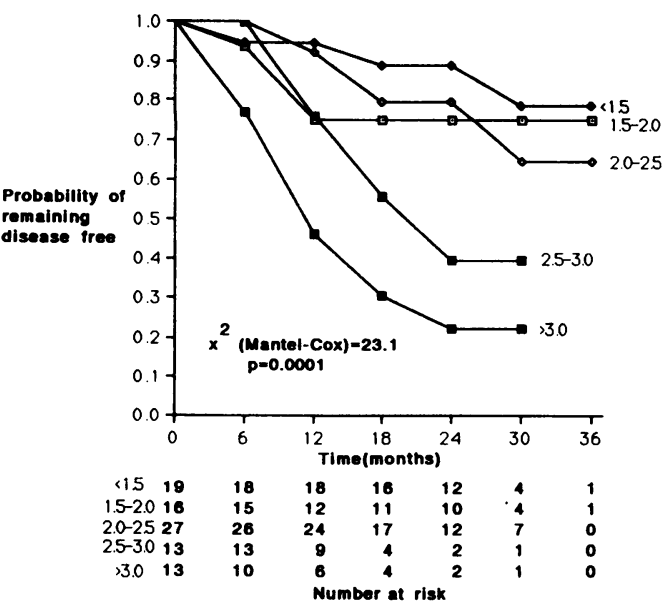

Figure 4 Probability of disease free state against time of patient groups identified using a prognostic index based on EGFR expression, lymph node stage, and histological grade.

study with lymph node stage or tumour size, both of which are time dependent prognostic variables. Although the presence of EGFR did not correlate with overall histological grade, its relation with nuclear pleomorphism is interesting. Nuclear size has, in some studies, been shown to be an important prognostic determinant in its own right and our results would suggest that the larger a breast cancer nucleus the greater the likelihood is that it will express EGFR.

The multivariate analysis presented in this study confirms that EGFR expression is a strong prognostic factor in primary breast carcinoma in its own right. In the absence of knowledge of histological grade, as shown in the multivariate analysis, EGFR is particularly powerful. An EGFR immunoassay is relatively straightforward to perform and involves less subjectivity in its interpretation than histological grading and could provide an alternative to conventional histological grading.

The strong inverse correlation between EGFR positivity and oestrogen receptor expression has also been shown in other studies, ${ }^{79}$ although the exact meaning of this association is unclear. It has been proposed that EGFR positivity provides a means of defining a subgroup of oestrogen receptor negative patients with a particularly poor prognosis, ${ }^{10}$ and our results support this evidence (fig 3). Multivariate analysis of our results (fig 8) from this study and in previous larger studies, ${ }^{12}$ however, have failed to show any independent prognostic significance to oestrogen receptor content in the presence of the powerful prognostic information provided by lymph node stage, tumour size, and histological grade. We suggest that EGFR expression combined as a prognostic index with lymph node and histological grade provides a superior means of discriminating groups of patients with very different prognosis (fig 4) than by using only EGFR expression and oestrogen receptor content. The index could currently be used to identify a group of patients with a particularly poor prognosis who would most benefit from systemic adjuvant therapy such as chemo- 
therapy or hormonal manipulation. It must be stated, however, that before this could be implemented this index would require confirmation in a prospective study in a larger group of patients.

There has been considerable recent interest in the prognostic effect of the oncoprotein cerb $B 2$ in breast carcinoma. ${ }^{19}$ CerbB2 is a membrane receptor which has a striking sequence homology with EGFR. ${ }^{20}$ Both EGFR expression and cerbB2 oncoprotein immunoreactivity can provide prognostic information in breast cancer, but to our knowledge there is no recognised association between these two similar membrane receptors. Further work is needed to examine any possible relation between them and their combined role in the management of breast cancer.

We are grateful to Professor Waterfield for donation of the antibody EGFR1, to Julie Rainbow for help with the manuscript, and to Jeff Gilbert and Keith Gordon for preparation of the illustrations. This work was supported by a grant from Trent Regional Health Authority.

1 Topnelli QJ, Sorof S. Epidermal growth factor requirements of cultured mammary gland. Nature 1980;285:251-2.

2 Kurachi H, Okamoto S, Okra T. Evidence for the involvement of the submandibular gland epidermal growth factor in mouse mammary tumourigenesis. Proc Natl Acad Sci 1985;82:5940-3

3 Dickson RB, Lippman ME. Estrogenic regulation of growth and polypeptide growth factor secretion in human breast carcinoma. Endocrine Review 1987;8:29-43.

4 Taylor-Papadimitriou J, Shearer M, Stopker MGP. Growth requirements of human mammary epithelial cells in requirements of human mammary

5 Osborne CK, Hamilton B, Nover M. Receptor binding and processing of epidermal growth factor by human breast cancer cells. J Clin Endocrinol Metab 1982;55:86-93.

6 Osborne CK, Hamilton B, Titus G, Livingstone RB. Epidermal growth factor-simulation of human breas cancer cells in culture. Cancer Res 1980;40:2361-9.

7 Pekonen F, Partanen S, Makinen T, Rutanen E. Receptors for epidermal growth factors and insulin like growth factor 1 and their relation to steroid receptors in human breast cancer. Cancer Res 1988;48:1343-7.

8 Sainsbury JRC, Malcolm AJ, Appleton DR, Farndon JR Harris AL. Presence of epidermal growth factor receptor Harris AL. Presence of epidermal growth factor receptor as an indicator of poor prognosis in patie
cancer. J Clin Pathol 1985;38:1225-8.

9 Sainsbury JRC, Farndon JR, Sherbet GU, Harris AL. Epidermal growth factor receptors and oestrogen receptors on human breast cancers. Lancet 1985;i:364-6.

10 Sainsbury JRC, Farndon JR, Needhamn GK, Malcolm AJ, Harris AL. Epidermal growth factor receptor status as predictor of early recurrence of and death from breast cancer. Lancet 1987; i:1398-402.

11 Todd JH, Dowle C, Williams MR, et al. Confirmation of a prognostic index in primary breast cancer. $\mathrm{Br} J$ Cancer prognostic index

12 Blamey RW, Davies CJ, Elston CW, Johnson J, Haybittle JL, Maynard PV. Prognostic factors in breast cancer-the JL, Maynard PV. Prognostic factors in breast cancer-the formation

13 Maynard PV, Blamey RW, Elston CW, Haybittle JL, Griffithe $\mathrm{K}$. Oestrogen receptor assay in primary breas cancer and early recurrence of the disease. Cancer Res 1978;38:4292-5.

14 Elston CW. Grading of invasive carcinoma of the breast. In: Page DL, Anderson TJ, eds. Diagnostic histopathology of the breast. Edinburgh: Churchill Livingstone, 1987: the breast.

15 Cox DR. Regression models and life tables. J Roy Stat Soc 1972;B:34187.

16 Cohen S. Isolation of a mouse submaxillary gland protein accelerating incisor eruption and eyelid opening in the new born animal. J Biol Chem 1962;237:1555.

17 Cohen S, Carpenter G. Human epidermal growth factor Isolation and chemical and biological properties. Proc Natl Acad Sci USA 1975;72:1317.

18 Gusterson B, Cowley G, Smith JA, Ozanne B. Cellular localisation of human epidermal growth factor receptor. Cell Biol Int Rep 1984;8:649-53.

19 Barnes DM. Breast cancer and a proto-oncogene. $\mathrm{Br} \mathrm{Med} \mathrm{J}$ 1989;299:1061.

20 Gullick WJ, Berger MS, Bennet PLP, Rothbard JB Waterfield MD. Expression of cerbB2 protein in normal and transformed cells. Int J Cancer 1987;40:7935. 